\title{
Therapeutic properties of cannabinoid drugs and marijuana in several disorders: A narrative review
}

\author{
Ricardo Iván Nanni Alvarado, ${ }^{1}$ Raúl Martín del Campo Sánchez, ${ }^{2}$ Valerio Villamil Salcedo³
}

\footnotetext{
1 Dirección General Adjunta de Políticas y Programas contra las Adicciones, CENADIC.

2 Dirección General de Políticas y Programas contra las Adicciones, CENADIC.

${ }^{3}$ Departamento de Investigación Clínica, Instituto Nacional de Psiquiatría Ramón de la Fuente Muñiz.
}

Correspondence:

Ricardo Iván Nanni Alvarado

Dirección General Adjunta de Políticas y Programas contra las Adicciones, CENADIC.

Av. Paseo de la Reforma 450, Piso 8 , Col. Juárez, Del. Cuauhtémoc, C.P. 06600, Ciudad de México, México

Phone: +52 (55) 3999-8976

Email: ricardonanni@yahoo.com.mx

Received: August 23, 2016

Accepted: February 15, 2017

doi:10.17711/SM.0185-3325. 2017.014

\begin{abstract}
Background. Anti-inflammatory, analgesic, anticonvulsant, and other effects have been attributed to cannabis, and so it has been widely used to treat several diseases. Objective. To assess the use and therapeutic effects of cannabinoid drugs and the cannabis plant in several diseases. Method. We carried out a narrative review of the literature that has reported the use of the cannabis plant (marijuana) and cannabinoid drugs (nabilone, cannabinol and dronabinol, among others). We conducted a search in Medline, Cochrane, SciELO and other web sites. Clinical, controlled, double-blind and randomized studies were included. The route of administration and the cannabinoid drugs used were assessed too. Results. Thirty-four studies were included. Nabilone was the cannabinoid drug more commonly used (12 studies), followed by delta-9-tetrahydrocannabinol (THC) (11 studies). It was also found that the marijuana plant and cannabinoid drugs were used to treat many symptoms or diseases. Two studies were reported for Gilles de la Tourette's syndrome. Discussion and conclusion. Many scientific studies on the marijuana plant and cannabinoid drugs conclude that these are not as effective as conventional medications and thus their benefits should be taken with caution.
\end{abstract}

Keywords: Marijuana plant, cannabinoid drugs, therapeutic effects, preclinical and clinical studies, evidence-based medicine, health policy.

\section{RESUMEN}

Antecedentes. A la planta de cannabis y a los fármacos cannabinoides se les han atribuido efectos antiinflamatorios, analgésicos y anticonvulsivantes, entre otros, y por ello se han utilizado para tratar diversas patologías. Objetivo. Evaluar el uso y los efectos terapéuticos de la planta de cannabis y los fármacos cannabinoides en diversas enfermedades. Método. Se utilizó un diseño descriptivo mediante la revisión narrativa de la literatura sobre el uso de la planta de cannabis (mariguana) y los fármacos cannabinoides (nabilona, cannabinol y dronabinol, entre otros) en los buscadores Medline, Cochrane, SciELO y otros. Se incluyeron sólo los estudios clínicos, controlados, doble ciego y aleatorizados, así como la vía de administración y el fármaco cannabinoide utilizado. Resultados. Treinta y cuatro estudios cumplieron con los criterios de inclusión. La nabilona fue el fármaco más empleado (12 estudios), seguida del delta-9-tetrahidrocannabinol (THC) (11 estudios). Tanto la planta como los fármacos cannabinoides se utilizaron para tratar diversos síntomas o enfermedades. Dos estudios reportaron su uso para el síndrome de Gilles de la Tourette. Discusión y conclusión. La mayoría de los estudios revisados indican que la efectividad de la planta de mariguana o de los fármacos cannabinoides no es superior a la de los fármacos convencionales y que sus beneficios deben tomarse con cautela.

Palabras clave: Planta de mariguana, fármacos cannabinoides, efectos terapéuticos, estudios clínicos, medicina basada en pruebas, política sanitaria. 


\section{BACKGROUND}

The cannabis sativa plant contains more than 60 phytocannabinoids of which delta-9-tetrahydrocannabinol (THC) is the most abundant (Potter et al., 2008; "van Laar et al., 2015"). Among the other cannabinoids, the most studied ones are dronabinol (DBN) and nabilone, followed by cannabinol (CBN), cannabidiol (CBD), which seems to possess some anti-inflammatory, analgesic (Hohmann \& Suplita, 2006; Rea, Roche \& Finn, 2007; Jhaveri et al., 2008), anti-schemic (Lamontagne et al., 2006), antipsychotic (Leweke, Koethe \& Gerth, 2005), ansiolitic (Crippa et al., 2011), and anti-epileptic effects (Mortati, Dworetzky \& Devinsky, 2007); and finally, cannabigerol (CBG) and cannabicromeno (CBC) (Barceloux, 2012), which possess some properties which have been studied mainly in preclinical or animal models. Some other properties of the cannabinoid drugs have been tested on type I diabetes (Di Marzo, Piscitelli \& Mechoulam, 2011; Horváth et al., 2012), the immunological system (Malek, 2008; Bihl et al., 2011), and cancer (Hermanson \& Marnett, 2011; Sarfaraz et al., 2008; McAllister et al., 2007; McKallip et al., 2006). These so diverse physiological effects of cannabinoids are due to the existence of specific receptors distributed in some body organs and systems. This has drawn the attention of the scientific community for study and research.

Despite a long list of expected potential benefits, these have been difficult to assess because many of them are biphasic, that is to say, they initially present a higher acute response with low doses, which quickly decrease with their repeated administration [tachyphylaxie] (Fernández-Ruiz et al., 2000), making it necessary to gradually consume higher doses to reach the same effects which were originally achieved [tolerance] (Maldonado, Valverde \& Berrendero, 2006).

The pertinence and opportunity to scientifically approach such a relevant theme as is the medical justification of the therapeutic use of cannabis is framed in a moment of debate in the public opinion and its media influence. Mexico's Consejo Nacional de Salud (National Health Council), through the 25/V/CONASAVI/2014 Agreement on the eventual legalization of marijuana, states:

In the face of the debate which has arisen in different forums and organisms about the legalization of marijuana, the opinion of the members of the Consejo Nacional de Salud (National Health Council) is that, before making a decision on the matter, an evidence-based assessment about the harmful effects which its consumption brings about for human health should be made and they consider that legalization is not the matter under discussion. The issue should be focused in warranting the protection of the Mexican population health as established in article 40 of the Constitution of the Mexican United States and that this is a fundamental human right.
In the light of this situation, the questions the researchers made themselves before initiating the study were: 1 . Does cannabis have in its different forms any therapeutic effects?, and, being this the case, 2. Which symptoms or diseases are the most benefited?; and 3. Which of the drugs or cannabis plant are the most beneficial?

The objective of this paper was to assess, through a narrative search of the bibliography, the use and therapeutic effects of the cannabis plant and cannabinoid drugs for the treatment of several symptoms or diseases. Their efficacy over the conventional treatment or the prototypical drug was also evaluated.

\section{METHOD}

A search of the bibliography on the medicinal use of the cannabis plant and cannabinoid drugs to treat symptoms and diseases was carried out. The search was made in the websites Medline, Cochrane, PubMed, LILACS, PsycINFO, Psychology and Behavioral Sciences Collection, DynaMed, Google academic, Scopus, Embase.com and SciELO from 1970 to 2015. The keywords used both in English and Spanish were: cannabis, marijuana, cannabinoid system, evidence-based medicine, therapeutic and harmful effects, medical uses, cannabinoid drugs, clinical trials, case-control studies and effectiveness. Psychiatry post-graduate students were assigned the search duties. They were asked to look for, as a first inclusion criterion, articles on the cannabis plant and cannabinoid drugs with medical applications from 1979 to 2015 . They found 301 articles with these features. The second process was to classify the articles according to their methodological design and to select those which were clinical trials, controlled, double-blind cross-over, and randomized (34 studies) (Table 1). In each one of these, the reported therapeutic effect, its effect on the symptom or disease on which it was used, the type of cannabinoid drug or cannabis plant employed and the administration route were assessed. Other variables, such as the number of participants, doses, time of administration and control group, were not assessed because there was such a high heterogeneity among them that they did not allow any comparison. The remaining articles were considered as uncontrolled clinical studies with methodological inconsistencies, case reports or anecdotic accounts (267 studies) (CONADIC, 2014) because they did not include the doses, administration route or sample randomization, or else they did not clearly specify the study procedure.

To consider all the studies conducted and their reported results was the reason to include all the articles where the cannabis therapeutic use from 1970 to 2015 was mentioned. Nevertheless, only the results from the studies which met the inclusion criteria will be presented. Articles where only the abstract could be accessed or whose results were not published in any online access journal were excluded. 
Table 1

Studies reported according to methodology and results

Authors Objective Main results and conclusions

Frytak et al., 1979. ${ }^{1}$

To evaluate antiemetic activity of THC in com
parison with prochlorperazine and placebo.

Kluin-Neleman, Neleman, To evaluate the effect of THC as an antiemetic in Meuwissen \& Maes, 1979. ${ }^{2}$ patients treated with cancer chemotherapy.

Neidhart, Gagen, Wilson \& To evaluate the efficacy and toxicity of THC and Young, $1981 .^{1}$

Sallan, Cronin, Zelen \& Zin- To compare the antiemetic effect of THC and berg, $1980 .^{2}$

Meiri et al., 2007.2 prochlorperazine. To compare the efficacy and tolerability of Sixty-four patients were randomized. Total response was simdronabinol and ondansetron for delayed chemo- ilar with dronabinol (54\%), ondansetron (58\%), and combinatherapy-induced nausea and vomiting. tion therapy (47\%) versus placebo $(20 \%)$.

Crawford \& Buckman, To compare the efficacy and tolerability of nabi- Thirty-two patients were entered into the study. There was no 1986. ${ }^{1} \quad$ lone versus metoclopramide to treat vomiting. difference between the two treatments in the overall incidence or severity of vomiting; subgroup of patients who received metoclopramide had a substantial reduction in episodes of vomiting.

Cunningham et al., 1988. ${ }^{4}$ To compare the efficacy of nabilone and Seventy patients completed the cross-over assessment. It was prochlorperazine versus metoclopramide and significantly favoured metoclopramide and dexamethasone. dexamethasone.

George, Pejovic, Thuaire, To compare nabilone in cancer patients treated Twenty patients were included. Nabilone in comparison with Kramar \& Wolff, 1982. ${ }^{1} \quad$ with cisplatin. chlorpromazine did not significantly reduce vomiting.

Jones, Durant, Greco \& To evaluate nabilone versus placebo in chemo- Fifty-four patients were entered. Patients experienced less Robertone, 1982. ${ }^{2} \quad$ therapy-induced nausea and vomiting. vomiting and nausea while receiving nabilone compared to placebo. Side effects were common with nabilone but acceptable.

Priestman, Priestman \& Comparing nabilone versus metoclopramide to Forty patients with emesis were included. There was no difCanney, 1987. ${ }^{5} \quad$ control emesis induced by radiation.

Steele, Gralla, Braun Jr. \& To compare the effects of nabilone and prochlor- Thirty patients receiving cancer chemotherapy were included. Young, $1980 .{ }^{5}$ perazine on chemotherapy-induced emesis. Both nabilone and prochlorperazine appeared to produce antiemetic effects.

Hutcheon et al., 1983. ${ }^{3} \quad$ Comparison of levonantradol with chlorprom- One hundred and eight patients were included. Levonantradol azine in patients receiving their first cytotoxic is a more effective antiemetic than chlorpromazine. However, chemotherapy. its use generates a high incidence of unacceptable central nervous system side-effects.

Lucraft \& Palmer, 1982. ${ }^{1} \quad$ Comparison of the antiemetic effect of chlor- Both drugs were well tolerated. The frequency of vomiting was promazine with levonantradol. $\quad$ similar in all groups.

Abrams et al., 2003. ${ }^{1} \quad$ To determine the short-term effects of smoked Sixty-two patients were eligible. Smoked and oral cannabimarijuana on the viral load in HIV-infected pa- noids did not seem to be unsafe in people with HIV infection tients. with respect to HIV RNA levels, CD4+ and CD8+ cell counts, or protease inhibitor levels over a 21-day treatment.

Strasser et al., 2006. ${ }^{1} \quad$ To compare the effects of the cannabis extract, Two-hundred and forty three patients were randomly assigned. THC and placebo on appetite and quality of life No differences in patients' appetite or quality of life were found in patients with cancer-related anorexia-cachex- between three groups at the dosages investigated. ia syndrome.

Volicer, Stelly, Morris, Mc- To compare the effects of dronabinol versus pla- Fifteen patients were included. Dronabinol treatment deLaughlin \& Volicer, 1997. ${ }^{2}$ cebo in patients with Alzheimer's disease who creased the severity of anorexia versus placebo, but adverse were refusing food. reactions were more common.

Maurer, Henn, Dittrich \& To evaluate THC in antispastic and analgesic ef- A patient with spasticity and pain due to spinal cord injury was Hofmann, 1990. ${ }^{1} \quad$ fects in a single case.

Pooyania, Ethans, Szturm, To determine whether nabilone alleviates spas- Twelve patients were recruited. There was a significant deCasey \& Perry, 2010. ${ }^{2} \quad$ ticity in people with spinal cord injury.

Bach, 2004. ${ }^{1}$

\& To evaluate the effect of dronabinol on central Twenty four patients were icluded. Dronabinol has a modest neuropathic pain in patients with multiple scle- but clinically relevant analgesic effect on central pain. Adverse rosis. events were more frequent than placebo.

Wissel et al., 2006. ${ }^{2} \quad$ To evaluate the safety and efficacy of low dose Eleven of the 13 patients included completed the study. Nabitreatment with nabilone on spasticity. lone showed a significant decrease of pain. 
Table 1

Studies reported according to methodology and results (continued)

\begin{tabular}{|c|c|c|}
\hline Authors & Objective & Main results and conclusions \\
\hline $\begin{array}{l}\text { Frank, Serpell, Hughes, } \\
\text { Matthews \& Kapur, 2008. }\end{array}$ & $\begin{array}{l}\text { To compare the analgesic efficacy and side e } \\
\text { fects of nabilone with dihydrocodeine for chron } \\
\text { neuropathic pain. }\end{array}$ & $\begin{array}{l}\text { Ninety-six patients with chronic neuropathic pain were includ- } \\
\text { ed. Dihydrocodeine provided better pain relief than nabilone } \\
\text { and had slightly fewer side effects, although no major adverse } \\
\text { events occurred for either drug. }\end{array}$ \\
\hline Bestard \& Toth, $2011 .{ }^{6}$ & $\begin{array}{l}\text { To compare the efficacy of nabilone and gab- } \\
\text { apentin in patients with peripheral neuropathy. }\end{array}$ & $\begin{array}{l}\text { The benefits of monotherapy or adjuvant therapy with nabilone } \\
\text { appear comparable to gabapentin for the management of neu- } \\
\text { ropathic pain. }\end{array}$ \\
\hline
\end{tabular}

Noyes, Brunk, Avery \& To estimate the potency of the analgesic effects Thirty-six patients were selected for this study. THC induced Canter, $1975 . .^{6} \quad$ of THC and codeine and to compare their side side effects but at low doses was well tolerated. effects.

Ware, Fitzcharles, Joseph To determine the effects, quality of life, and glob- Thirty-two were recruited. Both nabilone and amitriptyline had \& Shir, 2010. $\quad$ al satisfaction of nabilone versus amitriptyline in a favorable effect; nabilone showed superiority for sleep qualipatients with fibromyalgia. ty. Adverse effects were more common with nabilone.

Pinsger et al., 2006. ${ }^{2} \quad$ To investigate the efficiency of nabilone on pa- Thirty patients were included. Nabilone treatment was superior tients with chronic pain.

Ostenfeld et al., 2011. ${ }^{1} \quad$ To evaluate the efficacy of GW842166 versus Ibuprofen and GW842166 demonstrated clinically meaningful ibuprofen in acute pain. analgesia in the setting of acute dental pain.

Weber, Goldman Truniger, To determine the effect of THC on cramps in Twenty-two patients participated in the study. THC was well $2010 .^{2}$ amyotrophic lateral sclerosis patients. tolerated.

Freeman et al., 2006. ${ }^{1} \quad$ To test whether cannabinoids reduce urge in- The multicentric study randomized 630 patients to receive oral continence episodes without affecting voiding in administration of cannabis extract, THC or placebo. Cannabis patients with multiple sclerosis. extract and THC showed significant effects over placebo.

Brady et al., 2004. ${ }^{6} \quad$ To evaluate the safety, tolerability, and efficacy Twenty-one patients were recruited. There were few side efof THC and cannabidiol in bladder dysfunction. fects, and cannabis-based medicinal extracts were safe and effective treatment for urinary dysfunction in patients with multiple sclerosis.

Esfandyari et al., 2007. ${ }^{1}$ To compare the effects of dronabinol and place- Fifty-two volunteers were randomized. Dronabinol relaxes the bo on colonic motility and sensation in healthy colon and reduces postprandial colonic motility and tone. Involunteers. crease in sensation ratings to distension suggest central modulation of perception.

Müller-Vahl et al., 2002. ${ }^{2}$ To evaluate the treatment of Tourette's syn- Twelve patients were included. There was a significant imdrome with THC. provement of tics and obsessive-compulsive behavior after treatment with THC compared to placebo.

Müller-Vahl et al., 2003. ${ }^{1} \quad$ To evaluate THC effectiveness in the treatment Twenty-four patients with Tourette's syndrome were included. of tics in Tourette's syndrome. No serious adverse effects occurred. The THC is effective and safe in the treatment of tics. It can be hypothesized that the central cannabinoid receptor system might play a role in this pathology.

Carroll et al., 2004. ${ }^{2} \quad$ To examine the hypothesis of the beneficial effect Nineteen patients were randomized. Cannabis was well tolerof cannabis on dyskinesia in Parkinson disease. ated, and had no pro- or antiparkinsonian action.

Maas et al., 2006. ${ }^{1}$

To study the efficacy and safety of dexanabinol Eighty hundred and forty-six patients were included. Patients in severe traumatic brain injury. in the dexanabinol and in the placebo group had an unfavourable outcome. Dexanabinol is safe, but is not efficacious in the treatment of traumatic brain injury.

Note: THC=Delta-9-tetrahydrocannabinol; ${ }^{1}$ Randomized and Double-blind study; ${ }^{2}$ Double-blind, placebo-controlled cross-over study; ${ }^{3} \mathrm{~A}$ randomized multicentre single blind; ${ }^{4}$ Open cross-over study; ${ }^{5}$ Randomized double-blind cross-over study; ${ }^{6}$ Open-label study.

\section{RESULTS}

In total, 301 articles were found. There were 34 clinical trials, double-blind, cross-over, and randomized studies. The cannabinoid drugs used were: delta-9-tetrahydrocannabinol (THC) (11 studies), THC + cannabidiol (two studies), cannabidiol (one study), dronabinol (five studies), nabilone (11 studies), levonantradol (two studies), GW842166 (one study), and dexabinol (one study).
From the 34 studies, one was carried out in gastrointestinal disorders, four in neurological, nine in different kinds of pain, 14 in nauseas and vomiting secondary to medical treatment, two in appetite loss due to some medical condition and two studies in urologic diseases, while only two articles reported the use of these substances in treatment of Gilles de la Tourette's syndrome (Figure 1).

Regarding the administration route, the most common was the oral or sublingual one (90\%). 


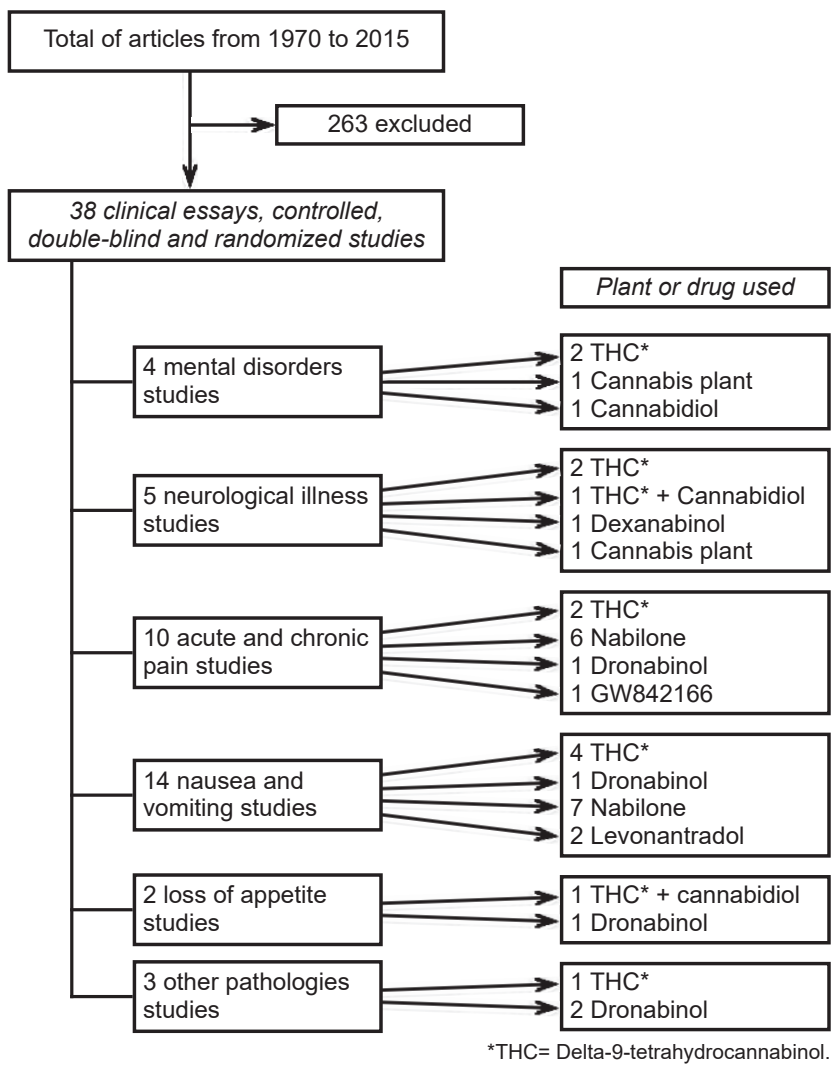

Figure 1. Reported studies.

\section{DISCUSSION AND CONCLUSION}

Most studies reached the conclusion that cannabinoid drugs are not more effective than most common or conventional medications. This was also the case with the use of the cannabis plant where the two studies that used it did not report more effectiveness than conventional medications. However, the type of cannabis plant used in these two studies was not also specified because the THC concentration may vary considerably from $10 \%$ to $30 \%$, not to speak of the new varieties which may even contain up to $40 \%$ of THC (Potter et al., 2008; van Laar et al., 2015). This influences both their therapeutic efficacy and their side effects.

A noteworthy difference between the cannabis plant and cannabinoid drugs is that the former presents a higher acute response with a low dose, and consequently there is the risk that this effect decreases with its repeated administration. This may result in the need to increase the dose to reach the same effects which could in turn provoke its chronic use and an increase in the secondary effects. Cannabinoid drugs have not reported this same effect (Potter et al., 2008; van Laar et al., 2015).

While some cannabinoid drugs have been approved for medical use, they have nevertheless restrictions as the use of these medications must be carefully monitored and they must not be administered to individuals under 18 years old or with a psychiatric record (especially schizophrenia) (Leweke, Koethe \& Gerth, 2005).

Likewise, a case-control study reported that the daily use of cannabis increased five fold the risk of suffering a psychotic disorder among cannabis users compared with non-users (di Forti et al., 2015). This points out to the need to be more careful with individuals prone to psychotic disorders as is the case with subjects with schizophrenia.

Another important aspect found in the 301 articles under scrutiny were the serious ethical implications, such as the use of the marijuana plant to treat nauseas or vomit secondary to pregnancy or to arouse appetite in geriatric patients. All these have their limitations given their risk of provoking theratogenic harms or worsening old people's health.

Results from studies carried out with patients with mild or moderate pathologies -such as acute pain for different causes, nausea and vomiting, or loss of appetite in geriatric patients- do not justify submitting patients to such a potential risk as there are other approved drugs without major side effects (CONADIC, 2014). Being this the case, marijuana is only approved to reduce the symptoms of some diseases or the secondary/undesirable/side effects of some other medical or chirurgical handlings, but occupying only a secondary position as a line of treatment.

It is also necessary to say that the studies reviewed here have a short-term basis and so no follow-up has been given as to their long-term effect in individuals who received such a treatment once the research -mainly in the studies concerning the cannabis plant- was finished.

In short, according to the evidence-based medicine model, the medical indications of commercial cannabinoid drugs are minimal and all are replaceable with other medications whose efficacy and side effects are perfectly wellknown.

In the light of their heterogeneity, the reviewed articles do not show a solid scientific support of the effectiveness of the medical use of the cannabis plant or its superiority versus conventional treatments and so its usefulness for therapeutic ends is limited. Other studies reach the same conclusions (del Bosque et al., 2013).

Despite which has been exposed so far, it is worth pointing out that multi-centric and open label studies have been reported recently, especially about the Dravet syndrome and the Lennox-Gastaut syndrome, both of which report the tolerability and efficacy of cannabidiol as an alternative therapeutic option for cases with resistant epilepsy. These studies were mainly carried out in pediatric population, and they yielded apparently promising results in their preliminary phases (Devinsky et al., 2016; Press, Knupp \& Chapman, 2015; Hussain et al., 2015).

The strengths and limitations of this paper are presented next. 


\section{Strengths}

This is one of the few articles to carry out a search in the last 40 years about cannabinoid drugs and the marijuana plant, their medical use and the ethical dilemmas surrounding the issue. A wide review was conducted to reach conclusions which are closer to the possible benefits of cannabinoid drugs. This review tries to guide decision-makers on health policies about what is known about the medical use of cannabinoid drugs, their benefits and consequences. Likewise, this review tries to shed light on the research level they are regarding therapeutic ends so that they are used as a phytocannabinoid extracted from the plant and not from the use of the cannabis plant in itself.

\section{Limitations}

To contrast the information, this article tried to include most of the articles reported about cannabinoid drugs and their medical use. However, this was not possible given the extent of the bibliography. Likewise, there is inaccessible medical literature because it is made up of internal documents or articles published in low-impact journals. Another limitation is that the review was carried out only online and no hard-copy journals were taken into account. So, articles written before the 90 's which were not uploaded to Internet may have been excluded.

Articles do not comment either on the cross-over tolerance by association of the cannabinoids with other medications or psychoactive substances. This effect may affect the short- and medium-term result. Another important aspect is the heterogeneity of the studies, which does not allow for a better analysis of the results or reaching statistically significant or more weighty conclusions, and so it is only possible to make a description of them. These and various other biases were observed in several studies and thus they were deleted from the beginning. Nevertheless, it is worth noting that biases were also observed in the studies included and these were not mentioned by the authors. All these limitations are an invitation to delve into the matter under a strict methodology.

Finally, unlike what was the case in the articles published mainly in the 70's and 80's, lately journals ask for a higher specification of the methodology, the statistical analysis, and the ethical considerations. In the light of this, it is not difficult to see that journals are now more exigent and vigilant about ethical and methodological aspects before accepting an article for publication.

\section{Funding}

None.

\section{Conflict of interests}

The authors declare they have no conflict of interest.

\section{REFERENCES}

Abrams, D. I., Hilton, J. F., Leiser, R. J., Shade, S. B., Elbeik, T. A., Aweeka, F. T., ... \& Deeks, S. G. (2003). Short-Term Effects of Cannabinoids in Patients with HIV-1 Infection. A Randomized, Placebo-Controlled Clinical Trial. Annals of Internal Medicine, 139(4), 258-266.

Barceloux, D. G. (2012). Medical toxicology of drug abuse: synthesized chemicals and psychoactive plants. New Jersey: John Wiley \& Sons.

Bestard, J. A., \& Toth, C. C. (2011). An Open-Label Comparison of Nabilone and Gabapentin as Adjuvant Therapy or Monotherapy in the Management of Neuropathic Pain in Patients with Peripheral Neuropathy. Pain Practice, 11(4), 353-368.

Bihl, F., Germain, C., Luci, C., \& Braud, V. M. (2011). Mechanisms of NK cell activation: CD4+ T cells enter the scene. Cellular and Molecular Life Sciences, $68(21), 3457$.

del Bosque, J., Fernández, C., Huesca, R. S., Díaz, D. B., López, A. D. G., Mairena, A. F., \& Alvarado, R. N. (2013). The Problem of Cannabis Use: the Role of the Ministry of Health. Salud Mental, 36(2), 133-142.

Brady, C. M., DasGupta, R., Dalton, C., Wiseman, O. J., Berkley, K. J., \& Fowler, C. J. (2004). An open-label pilot study of cannabis-based extracts for bladder dysfunction in advanced multiple sclerosis. Multiple Sclerosis, 10(4), 425-433.

Carroll, C. B., Bain, P. G., Teare, L., Liu, X., Joint, C., Wroath, C., ... \& Zajicek, J. P. (2004). Cannabis for dyskinesia in Parkinson disease. A randomized double-blind crossover study. Neurology, 63(7), 1245-1250.

Comisión Nacional contra las Adicciones (CONADIC). (2014). El uso médico del cannabis ¿tiene sustento científico?. Retrieved from http://www.conadic.salud. gob.mx/publicaciones/2015/uso_medico_cannabis.pdf

Crawford, S. M., \& Buckman, R. (1986). Nabilone and metoclopramide in the treatment of nausea and vomiting due to cisplatinum: a double blind study. Medical oncology and tumor pharmacotherapy, 3(1), 39-42.

Crippa, J. A. S., Derenusson, G. N., Ferrari, T. B., Wichert-Ana, L., Duran, F. L., Martin-Santos, R., \& Filho, A. S. (2011). Neural basis of anxiolytic effects of cannabidiol (CBD) in generalized social anxiety disorder: a preliminary report. Journal of Psychopharmacology, 25(1), 121-130.

Cunningham, D., Bradley, C. J., Forrest, G. J., Hutcheon, A. W., Adams, L., Sneddon, M., \& Kaye, S. B. (1988). A randomized trial of oral nabilone and prochlorperazine compared to intravenous metoclopramide and dexamethasone in the treatment of nausea and vomiting induced by chemotherapy regimens containing cisplatin or cisplatin analogues. European Journal of Cancer and Clinical Oncology, 24(4), 685-689.

Devinsky, O., Marsh, E., Friedman, D., Thiele, E., Laux, L., Sullivan, J., \& Wong, M. (2016). Cannabidiol in patients with treatment-resistant epilepsy: an open-label interventional trial. The Lancet Neurology, 15(3), 270-278.

Esfandyari, T., Camilleri, M., Busciglio, I., Burton, D., Baxter, K., \& Zinsmeister, A. R. (2007). Effects of a cannabinoid receptor agonist on colonic motor and sensory functions in humans: a randomized, placebo-controlled study. American Journal of Physiology-Gastrointestinal and Liver Physiology, 293(1), G137-G145.

Fernández-Ruiz, J., Berrendero, F., Hernández, M. L., \& Ramos, J. A. (2000). The endogenous cannabinoid system and brain development. Trends in neurosciences, 23(1), 14-20.

di Forti, M., Marconi, A., Carra, E., Fraietta, S., Trotta, A., Bonomo, M., \& Stilo, S. A. (2015). Proportion of patients in south London with first-episode psychosis attributable to use of high potency cannabis: a case-control study. The Lancet Psychiatry, 2(3), 233-238. doi: 10.1016/S2215-0366(14)00117-5

Frank, B., Serpell, M. G., Hughes, J., Matthews, J. N. S., \& Kapur, D. (2008). Comparison of analgesic effects and patient tolerability of nabilone and dihydrocodeine for chronic neuropathic pain: randomised, crossover, double blind study. BMJ, 336(7637), 199-201.

Freeman, R. M., Adekanmi, O., Waterfield, M. R., Waterfield, A. E., Wright, D., \& Zajicek, J. (2006). The effect of cannabis on urge incontinence in patients with multiple sclerosis: a multicentre, randomised placebo-controlled trial (CAMSLUTS). International Urogynecology Journal, 17(6), 636-641.

Frytak, S., Moertel, C. G., O'fallon, J. R., Rubin, J., Creagan, E. T., O'connell, M. J., \& Schwartau, N. W. (1979). Delta-9-Tetrahydrocannabinol as an Antiemetic for 
Patients Receiving Cancer Chemotherapy. A Comparison with Prochlorperazine and a Placebo. Annals of Internal Medicine, 91(6), 825-830.

George, M., Pejovic, M. H., Thuaire, M., Kramar, A., \& Wolff, J. P. (1982). Randomized comparative trial of a new anti-emetic: nabilone, in cancer patients treated with cisplatin. Biomedicine \& Pharmacotherapy, 37(1), 24-27.

Hermanson, D. J., \& Marnett, L. J. (2011). Cannabinoids, endocannabinoids, and cancer. Cancer Metastasis Review, 30(3-4), 599-612. doi:10.1007/s10555-011-9318-8.

Hohmann, A. G., \& Suplita, R. L. (2006). Endocannabinoid mechanisms of pain modulation. The AAPS Journal, 8(4), E693-E708.

Horváth, B., Mukhopadhyay, P., Haskó, G., \& Pacher, P. (2012). The endocannabinoid system and plant-derived cannabinoids in diabetes and diabetic complications. The American Journal of Pathology, 180(2), 432-442.

Hussain, S. A., Zhou, R., Jacobson, C., Weng, J., Cheng, E., Lay, J., \& Sankar, R. (2015). Perceived efficacy of cannabidiol-enriched cannabis extracts for treatment of pediatric epilepsy: a potential role for infantile spasms and LennoxGastaut syndrome. Epilepsy \& Behavior, 47, 138-141.

Hutcheon, A. W., Palmer, J. B., Soukop, M., Cunningham, D., McArdle, C., Welsh, J., \& Cash, H. (1983). A randomised multicentre single blind comparison of a cannabinoid anti-emetic (levonantradol) with chlorpromazine in patients receiving their first cytotoxic chemotherapy. European Journal of Cancer and Clinical Oncology, 19(8), 1087-1090.

Jhaveri, M. D., Elmes, S. J. R., Richardson, D., Barrett, D. A., Kendall, D. A., Mason, R., \& Chapman, V. (2008). Evidence for a novel functional role of cannabinoid CB2 receptors in the thalamus of neuropathic rats. European Journal of Neuroscience, 27(7), 1722-1730. doi:10.1111/j.1460-9568.2008.06162.x

Jones, S. E., Durant, J. R., Greco, F. A., \& Robertone, A. (1982). A multi-institutional Phase III study of nabilone vs. placebo in chemotherapy-induced nausea and vomiting. Cancer Treatment Reviews, 9, 45-48.

Kluin-Neleman, J. C., Neleman, F. A., Meuwissen, O. J., \& Maes, R. A. (1979). Delta 9-Tetrahydrocannabinol (THC) as an antiemetic in patients treated with cancer chemotherapy; a double-blind cross-over trial against placebo. Veterinary and human toxicology, 21(5), 338-340.

van Laar M., Cruts G., van Ooyen-Houben M., Croes, E., van der Pol, P., Meijer, R., \& Ketelaars, T. (2015). The Netherlands drug situation 2014: Report to the EMCDDA by the Reitox National Focal Point. Retrieved from: https://www. trimbos.n1/?act=winkeldl.download\&prod $=673$

Lamontagne, D., Lepicier, P., Lagneux, C., \& Bouchard, J. F. (2006). The endogenous cardiac cannabinoid system: a new protective mechanism. Archives des Maladies du Coeur et des Vaisseaux, 99(3), 242-6.

Leweke, F., Koethe, D., \& Gerth, C. (2005). Cannabidiol as an antipsychotic: a double-blind, controlled clinical trial of cannabidiol versus amisulpiride in acute schizophrenia. In 15th annual symposium on cannabinoids. Cannabinoid Research Society, Clearwater Beach, FL.

Lucraft, H. H., \& Palmer, M. K. (1982). Randomised clinical trial of levonantradol and chlorpromazine in the prevention of radiotherapy-induced vomiting. Clinical Radiology, 33(6), 621-622.

di Marzo, V., Piscitelli, F., \& Mechoulam, R. (2011). Cannabinoids and endocannabinoids in metabolic disorders with focus on diabetes. Diabetes-Perspectives in Drug Therapy (pp. 75-104). Springer Berlin Heidelberg.

Maas, A. I., Murray, G., Henney, H., Kassem, N., Legrand, V., Mangelus, M., \& Knoller, N. (2006). Efficacy and safety of dexanabinol in severe traumatic brain injury: results of a phase III randomised, placebo-controlled, clinical trial. The Lancet Neurology, 5(1), 38-45. doi:10.1016/S1474-4422(05)70253-2

Maldonado, R., Valverde, O., \& Berrendero, F. (2006). Involvement of the endocannabinoid system in drug addiction. Trends in neurosciences, 29(4), 225-232. doi:10.1016/j.tins.2006.01.008

Malek, T. R. (2008). The biology of interleukin-2. Annual Review of Immunology, $26,453-479$

Maurer, M., Henn, V., Dittrich, A., \& Hofmann, A. (1990). Delta-9-tetrahydrocannabinol shows antispastic and analgesic effects in a single case double-blind trial. European Archives of Psychiatry and Clinical Neuroscience, 240(1), $1-4$.

McAllister, S. D., Rigel T. C., Horowitz, M. P., Garcia, A., \& Desprez, P. Y. (2007). Cannabidiol as a novel inhibitor of Id-1 gene expression in aggressive breast cancer cells. Molecular Cancer Therapeutics, 6(11), 2921-2927.
McKallip, R. J., Jia, W., Schlomer, J., Warren, J. W., Nagarkatti, P. S., \& Nagarkatti, M. (2006). Cannabidiol-induced apoptosis in human leukemia cells: a novel role of cannabidiol in the regulation of p22phox and Nox4 expression. Molecular Pharmacology, 70(3), 897-908.

Meiri, E., Jhangiani, H., Vredenburgh, J. J., Barbato, L. M., Carter, F. J., Yang, H. M., \& Baranowski, V. (2007). Efficacy of dronabinol alone and in combination with ondansetron versus ondansetron alone for delayed chemotherapy-induced nausea and vomiting. Current Medical Research and Opinion, 23(3), 533-543.

Mortati, K., Dworetzky, B., \& Devinsky, O. (2007). Marijuana: an effective antiepileptic treatment in partial epilepsy? A case report and review of the literature. Reviews in Neurological Diseases, 4(2), 103-106.

Müller-Vahl, K. R., Schneider, U., Koblenz, A., Jöbges, M., Kolbe, H., Daldrup, T., \& Emrich, H. M. (2002). Treatment of Tourette's syndrome with $\Delta 9$-tetrahydrocannabinol (THC): a randomized crossover trial. Pharmacopsychiatry, 35(02), 57-61.

Müller-Vahl, K. R., Schneider, U., Prevedel, H., Theloe, K., Kolbe, H., Daldrup, T., \& Emrich, H. M. (2003). $\Delta 9$-tetrahydrocannabinol (THC) is effective in the treatment of tics in Tourette syndrome: A 6-week randomized trial. The Journal of Clinical Psychiatry, 64(4), 459-65.

Neidhart, J. A., Gagen, M. M., Wilson, H. E., \& Young, D. C. (1981). Comparative trial of the antiemetic effects of THC and haloperidol. The Journal of Clinical Pharmacology, 21(S1).

Noyes, R., Brunk, S. F., Avery, D. H., \& Canter, A. (1975). The analgesic properties of delta-9-tetrahydrocannabinol and codeine. Clinical Pharmacology \& Therapeutics, 18(1), 84-89.

Ostenfeld, T., Price, J., Albanese, M., Bullman, J., Guillard, F., Meyer, I., \& Milleri, S. (2011). A randomized, controlled study to investigate the analgesic efficacy of single doses of the cannabinoid receptor-2 agonist GW842166, ibuprofen or placebo in patients with acute pain following third molar tooth extraction. The Clinical Journal of Pain, 27(8), 668-676.

Pinsger, M., Schimetta, W., Volc, D., Hiermann, E., Riederer, F., \& Pölz, W. (2006). Benefits of an add-on treatment with the synthetic cannabinomimetic nabilone on patients with chronic pain--a randomized controlled trial. Wiener Klinische Wochenschrift, 118(11-12), 327-335.

Pooyania, S., Ethans, K., Szturm, T., Casey, A., \& Perry, D. (2010). A randomized, double-blinded, crossover pilot study assessing the effect of nabilone on spasticity in persons with spinal cord injury. Archives of Physical Medicine and Rehabilitation, 91(5), 703-707.

Potter, D. J., Clark, P., \& Brown, M. B. (2008). Potency of $\Delta 9-\mathrm{THC}$ and other cannabinoids in cannabis in England in 2005: Implications for psychoactivity and pharmacology. Journal of Forensic Sciences, 53(1), 90-94.

Press, C. A., Knupp, K. G., \& Chapman, K. E. (2015). Parental reporting of response to oral cannabis extracts for treatment of refractory epilepsy. Epilepsy \& Behavior, 45, 49-52.

Priestman, S. G., Priestman, T. J., \& Canney, P. A. (1987). A double-blind randomised cross-over comparison of nabilone and metoclopramide in the control of radiation-induced nausea. Clinical Radiology, 38(5), 543-544. doi:10.1016/S00099260(87)80151-4

Rea, K., Roche, M., \& Finn, D. P. (2007). Supraspinal modulation of pain by cannabinoids: the role of GABA and glutamate. British Journal of Pharmacology, 152(5), 633-648.

Sallan, S. E., Cronin, C., Zelen, M., \& Zinberg, N. E. (1980). Antiemetics in patients receiving chemotherapy for cancer: a randomized comparison of delta-9-tetrahydrocannabinol and prochlorperazine. New England Journal of Medicine, 302(3), 135-138.

Sarfaraz, S., Adhami, V. M., Syed, D. N., Afaq, F., \& Mukhtar, H. (2008). Cannabinoids for cancer treatment: progress and promise. Cancer Research, 68(2), 339-342.

Steele, N., Gralla, R. J., Braun Jr, D. W., \& Young, C. W. (1980). Double-blind comparison of the antiemetic effects of nabilone and prochlorperazine on chemotherapy-induced emesis. Cancer Treatment Reports, 64(2-3), 219-224.

Strasser, F., Luftner, D., Possinger, K., Ernst, G., Ruhstaller, T., Meissner, W., \& Cerny, T. (2006). Comparison of orally administered cannabis extract and delta-9-tetrahydrocannabinol in treating patients with cancer-related anorexia-cachexia syndrome: a multicenter, phase III, randomized, double-blind, 
placebo-controlled clinical trial from the Cannabis-In-Cachexia-Study-Group. Journal of Clinical Oncology, 24(21), 3394-3400.

Svendsen, K. B., Jensen, T. S., \& Bach, F. W. (2004). Does the cannabinoid dronabinol reduce central pain in multiple sclerosis? Randomised double blind placebo controlled crossover trial. BMJ, 329(7460), 253.

Volicer, L., Stelly, M., Morris, J., McLaughlin, J., \& Volicer, B. J. (1997). Effects of dronabinol on anorexia and disturbed behavior in patients with Alzheimer's disease. International Journal of Geriatric Psychiatry, 12, 913-919.

Ware, M. A., Fitzcharles, M. A., Joseph, L., \& Shir, Y. (2010). The effects of nabilone on sleep in fibromyalgia: results of a randomized controlled trial. Anesthesia \& Analgesia, 110(2), 604-610.
Weber, M., Goldman, B., \& Truniger, S. (2010). Tetrahydrocannabinol (THC) for cramps in amyotrophic lateral sclerosis: a randomised, double-blind crossover trial. Journal of Neurology, Neurosurgery \& Psychiatry, 81(10), 1135-1140.

Wissel, J., Haydn, T., Müller, J., Brenneis, C., Berger, T., Poewe, W., \& Schelosky, L. D. (2006). Low dose treatment with the synthetic cannabinoid Nabilone significantly reduces spasticity-related pain: a double-blind placebo-controlled crossover trial. Journal of Neurology, 253(10), 1337-1341. doi:10.1007/s00415-006$0218-8$ 